\title{
The effect of social fragmentation on public good provision: an experimental study
}

\author{
Surajeet Chakravarty and Miguel A. Fonseca*
}

\begin{abstract}
We study the role of social identity in determining the impact of social fragmentation on public good provision using laboratory experiments. We find that as long as there is some degree of social fragmentation, increasing it leads to lower public good provision. This is mainly because the share of those who contribute fully to the public good diminishes with social fragmentation, while the share of free-riders is unchanged, which suggests social identity preferences drive our result, as opposed to self-interest. Importantly, socially homogeneous groups do not generate the highest contributions: some social diversity is actually welfareimproving. Finally, social fragmentation is felt differently for visible minorities, whose contributions are higher than minority groups whose actions are not identifiable.
\end{abstract}

JEL - classification numbers: C92, D02, D03, H41

Keywords: Social Identity, Public Goods, Social Fragmentation, Experiments.

\footnotetext{
${ }^{*}$ Chakravarty: University of Exeter; Email: s.chakravarty@exeter.ac.uk; Tel: +44 (0)1392 263419; Fax: +44 (0)1392 263242.Fonseca: University of Exeter; Email: m.a.fonseca@exeter.ac.uk. We gratefully acknowledge financial support from the University of Exeter Economics Department and ESRC grant RES-000-22-3941. We thank Tim Miller for his excellent assistance with programming the software and help with running the sessions. We are also grateful to Yan Chen, Dirk Engelmann, Gareth Myles, Lise Vesterlund and Daniel Zizzo; participants at the 2009 European ESA, the 2010 World ESA, the 2012 RES, the 2012 European Econometric Society conferences; and participants at seminars at the University of Exeter, ETH Zurich and the University of Pittsburgh for their comments and suggestions. An earlier version of this paper circulated under the title "Social Identity, Group Composition and Public Good Provision: An Experimental Study." The usual disclaimer applies.
} 


\section{Introduction}

"In the presence of diversity, we hunker down. We act like turtles. The effect of diversity is worse than had been imagined. And it's not just that we don't trust people who are not like us. In diverse communities, we don't trust people who do look like us." Robert D. Putnam (2007)

We live in an ever increasingly diverse world, whether measured in terms of ethnicity, religion or language. For instance, in the US there has been an increase in the proportion of ethnic minorities. While currently accounting for roughly one third of the population, they are expected to become the majority in 2042 (US Census, 2009).

Increasing social and ethnic diversity in societies may have important economic consequences, namely on public good provision. Ethnic or social fragmentation has emerged as a potential explanation for low public good provision in settings as diverse as African countries (Easterly and Levine, 1997) and US cities (Alesina et al., 1999). A fundamental question is why this is the case.

The literature on the effect of social fragmentation on economic performance has identified two main causes for the negative relationship between higher fragmentation and public good provision. On one hand, different social or ethnic groups may prefer different public goods (Poterba, 1998). On the other hand, different social groups may dislike sharing a public good with one another (Luttmer, 2001).

Distinguishing between these two causes is very difficult. To see why, consider a hypothetical outdoors space between two neighbourhoods, each of whom is dominated by one of two distinct social groups, say Indians and Portuguese. This space is potentially suitable as a sports park, conditional on there being sufficient private investment by community members. Private provision of sports facilities may be insufficient because Indians prefer to play cricket, while the Portuguese may prefer soccer. Alternatively, it could be that the Indian and Portuguese communities do not want to share the space with each other due to discriminatory preferences. However, from the point of view of an outsider, it is impossible to ascertain why public good provision is low. 
Theories of inter-group relations in social sciences have argued that discriminatory behaviour across ethnic or religious lines stem from competition for resources (Allport, 1954; Sherif et al., 1988). Economists have broadly taken two approaches to model the role of social affiliation. The first approach emphasises that group affiliation is an important tool to overcome market imperfections by promoting trust among members of a given social group and therefore be able to overcome moral hazard problems (La Ferrara, 2003; Bowles and Gintis, 2004). At the core of this approach is a game-theoretic argument based on repeated interaction, in that more identical groups should be able to achieve and sustain cooperative outcomes as equilibria via internal mechanisms of monitoring and social norm enforcement.

The second is to assume that a sense of group identity enters individual preferences. In this sense, individuals define themselves as a function of the group(s) to which they belong. ${ }^{1}$ As such, an individual may shape his behaviour as a function of group norms (Akerlof and Kranton, 2000); or care not only about his well-being, but also about the well-being of his fellow group members (Alesina and La Ferrara, 2000; Shayo, 2009; Fehr and Hoff, 2011). This approach is in the spirit of social identity theory, which explains the basis for discriminatory behaviour across groups (Brewer, 1979; Tajfel and Turner, 1979).

Our paper investigates, using laboratory experiments, whether higher social fragmentation leads to lower public good provision and to what extent identity-based discrimination can explain such behaviour. We eliminate the possibility that different groups may prefer alternative public goods by allowing for only one public good to which members of both groups may contribute. We generate two artificial groups in the lab, and we exogenously change the degree of fragmentation by varying the relative size of each group in the population playing the public good game. This allows us to measure the interaction between social identity and fragmentation on public good provision cleanly.

We considered two information conditions in the main treatment: in one, subjects

\footnotetext{
${ }^{1}$ Tajfel (1970) argued that membership of social groups had an effect on individual behaviour even if such membership had no survival benefit.
} 
could observe the contributions of each individual as well as his social group membership (though never his actual identity). In the other condition, subjects could only see the total contribution made by the other five subjects.

We find that a higher degree of social fragmentation leads to significantly lower contribution levels and the highest contribution levels are observed with the lowest level of fragmentation. Interestingly, this result comes from a drop in the share of players who contribute maximally, rather than an increase in the fraction of free-riders, which remains roughly constant across treatments.

However, fully homogenous populations do not contribute more than highly fragmented ones and contribute less than minimally fragmented populations. This implies that an in-group affiliation is a powerful driver for cooperation, such that some diversity may be beneficial; however, such an affiliation only works in the presence of an out-group.

The impact of information on contributions is two-fold. On one hand, contributions are on average higher when individual contributions are identifiable than when information on aggregate contributions is available, irrespective of fragmentation levels. On the other hand, the comparative static effects of social fragmentation are more salient in the condition where only aggregate information is available. Furthermore, when individual contribution levels are available, we do not observe any differences between majorities and minorities; however, minorities contribute significantly less to the public good when only aggregate information is available.

The remainder of the paper is organised as follows. The following section briefly reviews the empirical literature on fragmentation, as well as the experimental literature on social identity. Section ?? outlines a simple model of social identity preferences which we use to set up the hypotheses underpinning the experiments. Section ?? outlines the experimental design and procedures and section ?? presents the results. Section ?? concludes the paper with a discussion of the results. 


\section{Summary of the Literature}

Recently economists have started to study the broader economic impact of social and ethnic fragmentation on economic performance (see Alesina and La Ferrara (2005) for an extensive review). Alesina et al. (1999) look at provision of public goods on a crosssection of African countries and find a negative correlation between ethnic fragmentation and the provision of such services. Khwaja (2009) finds that there is a negative relationship between social heterogeneity and successful maintenance of public projects. Finally Miguel and Gugerty (2005) find that schools in Kenya from fully homogeneous communities have 20 percent higher funding levels than schools in communities with the highest degree of heterogeneity. ${ }^{2}$

Tajfel and Turner (1979) first demonstrated the effect of group affiliation on behaviour using experimental data. They showed that subjects playing simple distribution games as a dictator would discriminate in favour of in-group members (and thus violating basic norms of equality), even when the basis for the existence of the group was quite minimal - in this case, it was based on subjects' preferences over paintings from two artists. This finding has since been replicated in a number of experimental studies (Haslam, 2004).

Most economics experiments focusing on the impact of group identity on cooperation have looked at pure in-group/out-group differences in two-player cooperation games, where a subject either plays against an in-group member or an out-group member. Notable exceptions are Eckel and Grossman (2005), who looked at a team production

\footnotetext{
${ }^{2}$ Other papers analysing social fragmentation and economic outcomes include La Porta et al. (1999) and Alesina et al. (2003) which find that ethnic fragmentation is negatively correlated with infrastructure quality, literacy and positively correlated with child mortality. Easterly and Levine (1997) find a negative correlation between growth and ethnic fragmentation. Anderson (2011) finds that Indian lower caste households living in villages which have a large upper caste majority have substantially less income than in villages dominated by lower castes. He attributes this to a breakdown of cross-caste trade in essential commodities like water. In microfinance, ethnic homogeneity can lead to higher repayment (Karlan, 2007) and socio-economic homogeneity results in lower default rates (Devereux and Fishe, 1993).
} 
experiment with groups of five. Their research question was whether eliciting a common identity within a group would raise effort levels. They found identity matters most when there is inter-group competition, i.e. when an out-group is made salient. In this literature, group affiliation was achieved using either pre-existing identities, such as gender (Brown-Kruse and Hummels, 1993; Cadsby and Maynes, 1998; Croson et al., 2008), membership of social groups (Solow and Kirkwood, 2002; Goette et al., 2006), or artificially-induced identities (Kramer and Brewer, 1984; Wit and Wilke, 1992; Eckel and Grossman, 2005; Charness et al., 2007.)

Regarding the effect of ethnic diversity, Espinosa and Garza (1985) and Cox et al. (1991) found that individuals from minority cooperated more with fellow minority participants than with majority subjects. Habyarimana et al. (2007) combined experimental methods with survey data and found public good provision was highest in areas when group composition was homogenous along ethnic lines.

\section{The Model}

In this section we will first propose a model of how individuals incorporate group identity into their preferences. We then apply this model to a linear public good provision game. We propose hypotheses to test the effect of group identity on public good provision when there are two distinct social groups, as well as the effect on contributions of varying the relative size of each group.

\subsection{Social Identity Preferences}

We analyse the impact of social identity by making social preferences contingent on group membership. We adapt the functional form proposed by McLeish and Oxoby (2007), where an individual maximises a combination of his payoffs and others payoffs, whose weights are a function of group membership: $u_{i}(x)=\alpha_{i}^{g} \bar{\pi}_{-i}+\left(1-\alpha_{i}^{g}\right) \pi_{i}(x)$, where $g \in\{I, O\}$ indicates whether the other player is an in-group $(I)$, or an out-group member $(O) . \bar{\pi}_{-i}$ is the average payoff of a member of group $g$, which we can interpret 
as the 'prototypical' member of group $g$.

Chen and $\mathrm{Li}$ (2009) estimate parameter values for $\alpha_{i, t}^{g}$ in a number of two-player games and find that $\alpha_{i}^{I}>\alpha_{i}^{O}$. In other words, individuals express higher concern for welfare of fellow in-group members than for out-group members.

We extend this model by allowing for the relative size of the in-group and out-group with which an individual plays to vary. ${ }^{3}$ We allow $\alpha_{i}^{g}$ to change as a function of the relative size of each group. In particular we postulate that $\alpha_{i}^{g}$ is a function of $S$, where $S \equiv \frac{\# I}{\# I+\# O}$. A large literature in psychology and sociology starting from Allport (1954) has looked at how inter-group discrimination varies as a function of the relative sizes of two groups and this literature forms the basis of our assumptions regarding the functional form of $\alpha_{i}^{g}(S)$.

An in-group is defined as a set of players who share a given characteristic and who identify themselves on the basis of that category. The out-group therefore, consists of the players who do not share these characteristics. Biases either for in-group members or against out-group members become salient only if players find others with different characteristics or belonging to another group. In other words, if all players belong to the same group then their attitude towards any individual would be undifferentiated. Therefore, we assume that $\alpha_{i}^{g}(0)=\alpha_{i}^{g}(1) \equiv \bar{\alpha}_{i}$. For the case where there is an in-group and an out-group, an individual can have two kind of biases: the positive bias towards in-group members and the negative bias towards out-group members. ${ }^{4}$

First, Brewer (1991) postulates that in-group identification is the product of two opposing needs. On one hand, individuals have a distinct need for inclusion. As such, they feel the need to identify herself with a collective unit. On the other hand, people

\footnotetext{
${ }^{3}$ While the empirical literature on fragmentation has considered cases where there are multiple social groups, we feel that restricting our attention to the two-group case is justified on two grounds. The use of two groups allows us to adequately capture the notion of fragmentation for purposes of analysis. Also, this paper is a first step in analysing the effect of fragmentation, and therefore, a two-group setup is a reasonable starting point.

${ }^{4}$ Allport (1954) first recognised that attachment towards one's in-groups should be seen separately from potential hostility towards out-groups.
} 
also have a need for distinctiveness: if a person is a member of an excessively large group, she feels the need to search for differentiation. Interpreting this in light of our model, this implies an inverted-U relationship between $\alpha_{i}^{I}(S)$ and $S$. Subjects will feel a strong in-group bias when they are in medium-sized groups, rather than in extremely large or small groups.

The second bias captured by $\alpha_{i}^{O}(S)$ is the threat that out-group members pose when groups are competing over physical resources (Levine and Campbell, 1972; Sherif, 1953.) So as hostility against out-group members increases as biases for in-group members increase. The implication is that $\alpha_{i}^{O}(S)$ will be U-shaped, where it is lowest (possibly negative) when the relative size of the in-group is intermediate, and highest when $S$ is either close to zero or close to one. ${ }^{5}$

\subsection{Public Good}

There are $n$ players, who participate in a VCM game. Players contribute $c_{i}$ towards a public good and receive a monetary payoff $\pi_{i}$ such that

$$
\pi_{i}:=y-c_{i}+a \sum_{j=1}^{n} c_{j}
$$

where $y$ is the initial endowment and $a$ is a parameter, $0<a<1<n a$. There are two distinct sub-groups in the $n$ player group. By belonging to one of the two sub-groups, player $i$ will have in-group members and out-group members. The number of out-group members are \#O and the number of in-group members are \#I=n-1-\#O.

Let player $i$ 's preferences be described by the following Von Neumann-Morgenstern utility function:

$$
u_{i}\left(\pi_{i}, \bar{\pi}_{-i}^{I}, \bar{\pi}_{-i}^{O}\right)=\left(1-\alpha_{i}^{I}(S)-\alpha_{i}^{O}(S)\right) \pi_{i}+\alpha_{i}^{I}(S) \bar{\pi}_{-i}^{I}+\alpha_{i}^{O}(S) \bar{\pi}_{-i}^{O}
$$

where $\alpha_{i}^{I}(S), \alpha_{i}^{O}(S)$ capture player $i$ 's concern towards in-group and out-group members'

\footnotetext{
${ }^{5}$ It is worth emphasising that $\alpha_{i}^{I}(S)$ and $\alpha_{i}^{O}(S)$ need not be symmetric. In fact, the shape of $\alpha_{i}^{I}(S)$ and $\alpha_{i}^{O}(S)$ will determine how social fragmentation affects contributions to the public good in equilibrium.
} 
welfare. ${ }^{6} \bar{\pi}_{-i}^{I}$ and $\bar{\pi}_{-i}^{O}$ are the average payoff of player i's in-group members and outgroup members. We assume that $\alpha_{i}^{I}(S), \alpha_{i}^{O}(S) \in[-1,1], \alpha_{i}^{I}(S)>\alpha_{i}^{O}(S)$ for all $S$ and $\alpha_{i}^{I}(S)+\alpha_{i}^{O}(S)<1$ for all $S$.

The first assumption is the same as considered by Chen and Li (2009), and the second assumption is based on the empirical estimations of $\alpha^{g}$ in the same study. Finally the third assumption is designed to avoid the case where a player would burn money to gain utility. The utility of player $i$ is therefore a combination of his own monetary payoff and the average of others' monetary payoff (both in-group and out-group.) Player $i$ can belong to the majority if $S>1 / 2$ or the minority if $S<1 / 2$. If $S=1 / 2$, then player $i$ is neither in a majority nor in a minority.

Combining equations ?? and ??, we obtain a utility function for player $i$ that is a function of own contribution $\left(c_{i}\right)$, average in-group contributions other than player $i$ $\left(\bar{c}_{-i}^{I}\right)$, average out-group contributions $\left(\bar{c}_{-i}^{O}\right), \alpha^{I}(S)$ and $\alpha^{O}(S)$ :

$$
u_{i}\left(c_{i}, \bar{c}_{-i}^{I}, \bar{c}_{-i}^{O}\right)=y-c_{i}+a \sum_{j=1}^{n} c_{j}+\alpha_{i}^{I}(S)\left(c_{i}-\bar{c}_{-i}^{I}\right)+\alpha_{i}^{O}(S)\left(c_{i}-\bar{c}_{-i}^{O}\right)
$$

\section{Experimental design and procedures}

We begin the section by outlining the experimental design which is the basis for our hypotheses. We then report the procedures used to collect the data.

\section{$4.1 \quad$ Experimental Design}

As stated earlier, we wish to test the impact on public good contribution of changes in the relative size of the in-group. We now construct the hypotheses for our experiment. Our experimental design, described in detail below, consists of a six-player linear public good game, with players belonging to one of two groups. We vary the relative size of the groups, from one extreme where all players belong to same group, to the case when there half of the players belong to one group and the other half belong to the other group.

\footnotetext{
${ }^{6}$ Although this functional form may be unfamiliar at first glance, it is easy to manipulate it such that it depends on differences in payoffs, as per Fehr and Schmidt (1999) or Charness and Rabin (2002).
} 
Table 1: Experimental design

\begin{tabular}{cccccc}
\hline \hline & \multicolumn{5}{c}{ Degree of Fragmentation } \\
\hline & Control & $6-0$ & $5-1$ & $4-2$ & $3-3$ \\
Public & 6 & 7 & 7 & 8 & 8 \\
RESTRICT & - & 6 & 6 & 6 & 6 \\
\hline \hline
\end{tabular}

This allows us to vary the level of fragmentation in a population and measure the levels of contribution to the public good as a function of fragmentation. ${ }^{7}$

Table ?? describes the experimental design. The two rows relate to two information treatments, Public and Restrict, on which we elaborate below. The columns describe the degree of fragmentation; the entries within the table indicate the number of independent groups we collected for that condition. The control treatment is when agents played the public good game without inducing group identity.

Our first hypothesis concerns the relevance of identity-driven preferences. As noted in the discussion of identity preferences, it is only in the presence of an out-group that both the favourable in-group and the adverse out-group biases are salient. Recall that for player $i, \alpha_{i}^{I}(S)$ and $\alpha_{i}^{O}(S)$ capture his in-group and out-group biases as a function of the relative social fragmentation $S$. As $S$ changes, so does the intensity of these biases. If the population consists of all players belonging to the same identity, then neither negative out-group biases nor positive in-group biases will exist. As such, contributions from players in populations where all players belong to the same group should be no different from contributions in populations where group identity is absent $\left(\alpha_{i}^{I}(S)=\alpha_{i}^{O}(S)=\overline{\alpha_{i}}\right)$. Therefore, average contributions in $6-0$ should be the same as average contributions in Control.

Hypothesis 1: Contributions to the public good by homogenous groups (6-0) are no different than contributions by anonymous groups (Control).

\footnotetext{
${ }^{7}$ While the word population is used in a very different context in game theory, we use it here to describe the set of six players playing the public goods game. This avoids using terms like sub-group to refer to each of the two social groups in the six-player game.
} 
Next, we set up the two main hypotheses of the paper. They address the relationship between social fragmentation (as measured by the relative proportion of each group in the population) and contributions to the public good. We are interested in the effect of fragmentation per se, as well as the comparative static effect of increasing the level of fragmentation on behaviour. ${ }^{8}$

When we replace a player in a homogeneous population 6 - 0 with an out-group member to construct a 5-1 group, we expect that identity-based biases will become salient. The presence of one outsider will introduce the positive in-group bias $\alpha_{i}^{I}(S)$ and the negative out-group bias $\alpha_{i}^{I}(S)$. Since there is just one out-group member the negative bias though present will be weak. Hence, we expect that there will be an increase in average contributions. As a result we get our next hypothesis.

Hypothesis 2: Increasing the number of out-group members from zero to one will lead to an increase in contributions to the public good.

According to the preferences and utility function described above, we hypothesise there will be a level of social fragmentation $S$ for which positive in-group and negative out-group biases will be largest. Taking the 5-1 condition as a starting point, as we increase the relative size of the minority, not only the minority group becomes more salient, but the majority group becomes less dominant. As such, the players' in-group biases should increase - majority members become less common, while minority members become part of a more meaningful group. Likewise, the negative out-group biases should also become more salient as the concern for one's group increases.

The effect of social fragmentation on contributions will depend on whether or not the favourable in-group bias will dominate the negative out-group bias. If, as the proportion of in-group $(S)$ falls, the favourable in-group bias, $\alpha_{i}^{I}(S)$, increases at a faster rate than the negative bias against the out-group members, $\alpha_{i}^{O}(S)$, then we should expect to see an increase in aggregate public good contribution as fragmentation increases. If instead,

\footnotetext{
${ }^{8}$ Our hypotheses are based on the symmetric equilibria of the public good game with social identity preferences. Please see Appendix for derivations.
} 
the negative out-group bias grows faster than the positive in-group bias then we will see a drop in public good contributions as fragmentation increases. Since we have neither a theoretical basis nor prior empirical results to determine which effect will dominate, we state our next hypotheses as follows:

Hypothesis 3a: Contributions to the public good game will be unaffected by social fragmentation.

If we reject Hypothesis 3a, we must specify the direction of the change in contributions due to changes in social fragmentation. This is formalised as follows:

Hypothesis 3b: Contributions to the public good game will decline as social fragmentation increases.

We now turn to the issue of how minorities will differ from majorities in terms of their contributions to the public good. As explained above, as the size of the minority increases, the positive in-group biases and negative out-group biases will become more salient.

Whether or not the majority players will contribute on average more than the minority players will depend on whether the negative biases towards out-group will dominate the positive in-group biases (which determine whether contributions go up or down as fragmentation increases), but also whether such changes are more pronounced for one group than for the other. If, for instance, the positive in-group biases dominate negative out-group biases, and that effect is more pronounced for minority players, then the minority players will on average contribute more than majority players. We state our hypothesis as:

Hypothesis 4: There will be no difference in contributions to the public good between majority and minority players.

We conclude this section by formalising the hypotheses regarding the two information conditions. The concept of social fragmentation in general, and the roles of majorities 
and minorities in particular, are applied typically to large populations and large groups. In that sense, there is a disconnect between what we can implement in the lab and what we observe in reality. To mitigate that discrepancy, we created two information conditions that capture the extent to which an individual's actions are more or less visible to the remainder of the population. In PUBLIC, it is possible to identify individuals' actions, although we do not allow reputation formation to occur (see the following section for details.) On one hand, individual visibility could arguably lead to higher contributions (Dana et al., 2011). On the other hand, this could cloud the effect of social fragmentation by emphasising individual-level contributions as opposed to group outcomes. To test for this effect, we implemented a second information condition, RESTRICT, where subjects were only given information about total contributions by the other five players in their population. We hypothesise that the comparative static effect of social fragmentation should be more salient in the condition where subjects only receive feedback about total contributions by the other five players.

Hypothesis 5: The effect of social fragmentation on contribution levels should be more salient in the RESTRICT condition than in the PUBLIC condition.

An interesting consequence of providing feedback on individual contributions is that in the 5-1 condition, members of the majority sub-group can identify the contribution of the minority individual (without compromising his anonymity). Recent evidence from trust games suggests that singling out an individual leads to significant changes in behaviour (Galeotti and Zizzo, 2012). In our setting, being able to identify the contributions of the minority player in the 5-1 condition could lead that individual to match the contribution of the majority and therefore contribute more than if his individual contribution was not possible to identify. This is our last hypothesis.

Hypothesis 6: Contributions by the minority element in the 5-1 condition will be higher in Public than in Restrict. 


\subsection{Experimental Procedures}

Before proceeding, a methodological note is warranted. To tackle our research question, unlike field studies which draw on real forms of identity such as language (Easterly and Levine, 1997; Alesina et al., 1999) or caste (Banerjee et al., 2005), we rely upon artificially induced identities, following the minimal group paradigm of Tajfel et al. (1971). We induce identity via participants' choices of paintings - an arbitrary task which is completely unrelated to the main focus of the experiment.

While an arbitrary identity has the drawback of artificiality, it also allows the experimenter to study the relevance of social identity on behaviour, while isolating the effect of individual preferences from the effect of a previous history of interaction. This is often not possible in the field. Furthermore, individuals may have multiple identities, each of whom may become salient depending on context (Sen, 2000). For instance, an individual may identify himself through his nationality, ethnicity or gender.

By combining an artificial identity with strict anonymity in choices, the experimenter can ensure that this is the only salient factor which influences choices. We can then study the effect of identity while teasing out repeated interaction effects. While studying the effect of particular types of identity such as gender or race is very important, we feel that working with a generic identity fits the purpose of this study best.

Our experimental procedure encompasses three stages. Stage 1 assigns participants to two different groups by eliciting their preferences over two artists' paintings. Stage 2 is a problem solving stage designed to reinforce participants' sense of affiliation to their group. Stage 3 is the actual public good game. We elaborate on each stage below.

Stage 1: Group Formation and Assignment. We induced social identity by employing a similar design to Chen and Li (2009). In the beginning of each session, participants saw five pairs of paintings; in each pair, one painting was done by Gustav Klee and the other by Wassily Kandinsky. ${ }^{9}$ Participants had to state their preference for one of the paintings in each pair. If participants preferred three or more Klee paintings, they

\footnotetext{
${ }^{9}$ The choice of paintings were chosen to be as similar as possible.
} 
were assigned to the Klee group. Otherwise they would be assigned to the Kandinsky group. This meant that we could not guarantee that exactly half the participants in a given session would go to one of the groups. However, the variation in group size across sessions was small. ${ }^{10}$

Stage 2: Identity Reinforcement. Once the Klee and Kandinsky groups were established, to reinforce their sense of identity, subjects were given a team-building exercise. This exercise consisted of identifying the authorship of two further paintings, one of which was painted by Klee and the other by Kandinsky. Participants were allowed to confer with fellow group members through a chat box for ten minutes. Communication was almost unrestricted; participants were not allowed to use abusive language and they were not allowed to identify themselves. Members of the Klee group could only see their own fellow group members comments and vice-versa. Participants received an individual payment for each painting they correctly identified.

Stage 3: Public Good Game. Following the painting identification stage, subjects were randomly allocated to populations of six. Subjects knew the composition of their own population, but they were not told of the composition of the other populations in the session.

The composition of each population is the main treatment variable. As described above, we considered four different treatments: homogeneous populations with six elements of the same type (6-0), and a further three treatments varying the degree of heterogeneity (5-1, 4-2, 3-3.) In addition, we ran an additional control treatment where we did not induce identity, which consisted only of Stage 3 (Control.)

All subjects played a standard Voluntary Contribution Game over twenty rounds with fixed matching. Subjects had twenty tokens that they had to allocate between a private and a public account. Payoffs were determined by the following equation, with the same parameters as Fehr and Gächter (2000).

\footnotetext{
${ }^{10}$ This also means we could not collect an equal amount of observations in all treatments.
} 


$$
\pi_{i}=20-c_{i}+0.4 \sum_{j=1}^{6} c_{j}
$$

In Public, at the end of each round, a screen informed subjects of the individual contributions by each of the other five subjects in their group, as well as his identity (Klee or Kandinsky.) The software randomised the order in which individual contributions we displayed on the screen from round to round, and this was common information. In RESTRICT the software only displayed that player's contribution, as well as the total contribution by the other five players to the public good.

Each session consisted of eighteen participants. At the end of the experiment, subjects were paid individually in cash. The experimental software was z-Tree (Fischbacher, 1997). A total of 234 undergraduate students participated in the experiment. Average payments were $£ 10.30$ (\$14.89). A copy of the instruction set is in the Appendix.

\section{Results}

We begin by looking at aggregate level treatment effects which establish our main result. We then proceed by investigating the effect fragmentation has on the distribution of contributions. We finalise the section by looking at individual level effects - in particular we measure how strength of group affiliation affects contributions.

\subsection{Aggregate Effects of Fragmentation}

Table ?? displays the OLS estimates of treatment effects on average contribution levels across 20 periods. Regression (1) looks at the effect of fragmentation as well as information conditions. A few facts stand out. Firstly, we find no difference in the coefficients on Control and $6-0 \times$ Public $(F(1,59)=2.06, p=0.16)$. This confirms our first hypothesis that in the absence of an out-group, a sense of identity is not relevant, and as such average contributions would not differ. 
Secondly, conditional on fragmentation level, the average contribution levels are higher in Public than in ReSTRICTED. While nominally so for all comparisons, the differences are only significant for the 4 -2 condition $(F(1,59)=3.87, p=0.05)$ and the 3-3 condition $(F(1,59)=4.15, p<0.05)$.

Thirdly, in both informational conditions, there is a jump in contributions from homogenous groups $(6-0)$ to heterogeneous groups (5-1). This jump is significant in Restricted $(F(1,59)=2.87, p=0.09)$, though not in Public $(F(1,59)=1.64, p=$ 0.21). Fourthly, there is a decline in contribution levels as the level of fragmentation increases, though that decline is only significant in the RESTRICTED condition.

Finally, we also find no statistical difference between the average contribution of the homogenous group, 6-0, and the fully fragmented group, 3-3, both in RESTRICTED and PUBLIC. ${ }^{11}$ This suggests that fully homogeneous groups perform no better than fully fragmented ones.

Regression (2) factors in the fact that there are minority and majority groups in two of the fragmentation conditions (5-1 and 4-2), and therefore allows for the possibility that minority and majority sub-groups in a given treatment may on average contribute different amounts. We find that there is a slight difference between majority and minority sub-groups in the RESTRICTED condition, but that difference is not significant. What is interesting is that the difference in coefficients between $6-0$ and $5-1$ $\times$ Restricted is significant $(F(1,59)=4.55, p=0.04$. $)$ Furthermore, the difference in average contributions between 5-strong majority and 4-strong majority is also significant $(5-1 \times$ Restricted $=4$-2 $\times$ Restricted $: F(1,59)=5.79, p=0.02$.$) However, we$ do not find significant differences when we make the same comparisons in the PUBLIC condition.

These results hint at the possibility that the minority members in the 5 -1 may be behaving differently in the Restricted and Public conditions, due to the fact that they are "quasi-identifiable". However, we find no significant difference between the average

\footnotetext{
11 5-1 $\times$ RESTRICTED $=4$ - $2 \times$ RESTRICTED: $F(1,59)=3.06, p=0.09 ; 6$ - $0 \times$ RESTRICTED $=3$ - $3 \times$ Restricted: $(F(1,59)=0.07, p=0.80 ; 6-0 \times$ Public $=3-3 \times$ Public: $F(1,59)=0.01, p=0.91$
} 


\begin{tabular}{|c|c|c|}
\hline Dep. var.: Contribution & $\overline{(1)}$ & $\overline{(2)}$ \\
\hline Control & $\begin{array}{l}9.75^{* *} \\
(0.89)\end{array}$ & $\begin{array}{l}9.75^{* *} \\
(0.89)\end{array}$ \\
\hline $6-0 \times$ PUBLIC & $\begin{array}{l}7.49^{* *} \\
(7.49)\end{array}$ & $\begin{array}{l}7.49^{* *} \\
(1.29)\end{array}$ \\
\hline 5-1 $\times$ PUBLIC & $\begin{array}{l}9.57^{* *} \\
(9.57)\end{array}$ & $\begin{array}{l}9.53^{* *} \\
(0.92)\end{array}$ \\
\hline $4-2 \times$ PUBLIC & $\begin{array}{l}7.93^{* *} \\
(7.93)\end{array}$ & $\begin{array}{l}7.92^{* *} \\
(1.15)\end{array}$ \\
\hline 3-3 × Public & $\begin{array}{l}7.65^{* *} \\
(7.65)\end{array}$ & $\begin{array}{l}7.65^{* *} \\
(0.39)\end{array}$ \\
\hline $4-2 \times$ PUBLIC $\times$ Min & & $\begin{array}{c}0.01 \\
(0.79)\end{array}$ \\
\hline $5-1 \times$ PuBliC $\times$ Min & & $\begin{array}{c}0.19 \\
(2.01)\end{array}$ \\
\hline 6-0 $\times$ RESTRICTED & $\begin{array}{l}5.60^{* *} \\
(0.28)\end{array}$ & $\begin{array}{l}5.60^{* *} \\
(0.28)\end{array}$ \\
\hline 5-1 × RESTRICTED & $\begin{array}{l}7.38^{* *} \\
(7.38)\end{array}$ & $\begin{array}{l}7.57^{* *} \\
(0.88)\end{array}$ \\
\hline 4-2 2 RESTRICTED & $\begin{array}{l}5.33^{* *} \\
(5.33)\end{array}$ & $\begin{array}{l}4.99^{* *} \\
(0.61)\end{array}$ \\
\hline 3-3 × RESTRICTED & $\begin{array}{l}5.31^{* *} \\
(5.31)\end{array}$ & $\begin{array}{l}5.31^{* *} \\
(1.08)\end{array}$ \\
\hline $4-2 \times$ RESTRICTED $\times$ Min & & $\begin{array}{c}1.01 \\
(0.87)\end{array}$ \\
\hline 5-1 $\times$ RESTRICTED $\times$ Min & & $\begin{array}{l}-1.12 \\
(1.23)\end{array}$ \\
\hline Observations & 7,200 & 7,200 \\
\hline R-squared & 0.58 & 0.58 \\
\hline
\end{tabular}

Table 2: OLS estimates of average treatment effects 
contributions of minority members in either information condition. A similar finding occurs in the 4-2 condition. ${ }^{12}$ The large standard errors on both $(5-1 \times$ RESTRICTED $\times$ Minority $)$ and $(5-1 \times$ PUBliC $\times$ Minority $)$ suggest a large variation in behaviour by the minority players in the 5-1 condition.

\subsection{Modelling the Contribution Decision}

Focusing the analysis on average effects neglects the possibility that social fragmentation may affect the distribution of contributions significantly while having a small impact on the average. We start by looking at the distributions of contribution levels for each of the fragmentation conditions in both information conditions.

Inspection of Figure ?? shows that the extent to which subjects free-ride on the public good (i.e. zero contributions) is higher in REsTRICT than in PUBLIC for all fragmentation levels. Furthermore, we see there is a jump in full contributions, when we go from a fully homogeneous group to the 5-1 case. Finally, we can observe a decline in full contributions as we increase the level of fragmentation in both PuBLIC and RESTRICT.

In order to econometrically model the contribution decision by subjects, we first note that subjects had to pick a contribution level between 0 and 20. In other words, the set of strategies was bounded above and below. Furthermore, Figure ?? shows there is a non-trivial amount of observations at both boundary points. As such, estimating the conditional mean of such a distribution through ordinary least squares will not only ignore important features of the distribution, it will not guarantee that predicted values are within the support of the strategy space.

We proceed by estimating a two-part model. First we normalise the data by dividing individual contributions by 20 , such that the support of the distribution of contributions is the unit interval. We model observations at the boundaries of the support of the

\footnotetext{
12 5-1 $\times$ Restricted $+5-1 \times$ Restricted $\times$ Minority $=5-1 \times$ Public $+5-1 \times$ Public $\times$ Minority: $F(1,59)=1.28, p=0.26 ; 4-2 \times$ Restricted +4 - $2 \times$ RESTRICTEd $\times$ Minority $=4$ - $2 \times$ PubliC + 4 -2 $\times$ PUBlic $\times$ Minority: $F(1,59)=1.35, p=0.25$.
} 

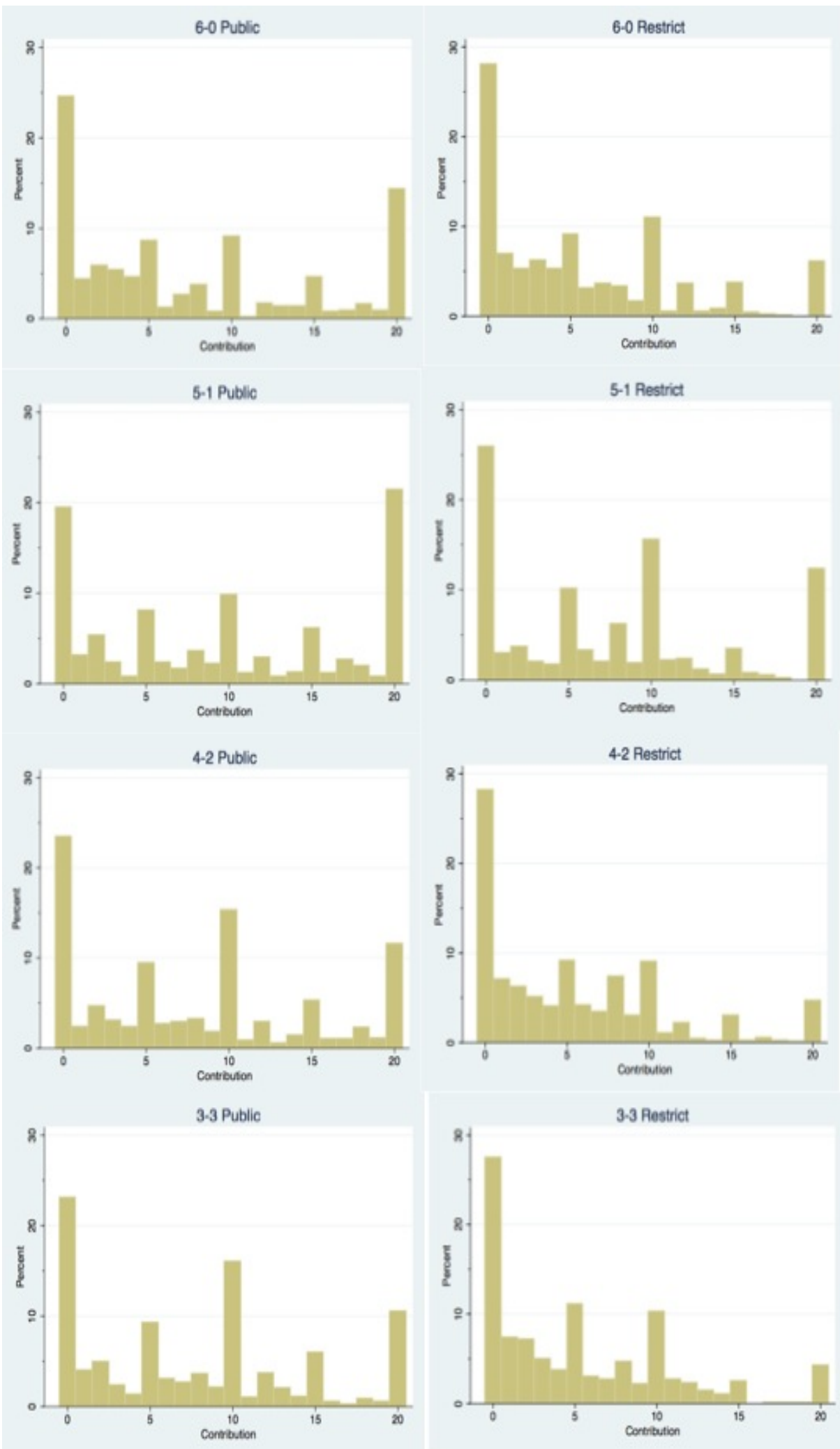

Figure 1: Distributions of contribution levels by fragmentation condition, PUBLIC and RESTRICT 
distribution (i.e. full free-riding and full contributions) as a discrete decision. We model the continuous component (i.e. contribution levels between 0 and 1) using a fractional regression model (see Papke and Wooldridge, 1996 and Ramalho et al., 2011). ${ }^{13}$

Our econometric modelling strategy explicitly distinguishes three types of decisions. The first is whether or not to free-ride and contribute nothing to the public good. The second is whether to contribute the whole endowment to the public good. This type of behaviour can be consistent with altruistic preferences, or by our model of social preferences and identity. These two decisions are modelled using a discrete choice model in the first part of our two-part model. Finally, the third alternative is how much to contribute to the public good, given that a subject neither wants to free-ride, nor to fully contribute his endowment. This is estimated using the second part of our econometric model.

Let $c_{i, t}$ denote the contribution level of individual $i$ in period $t$, which is observed on the interval $[0,1]$. We wish to estimate $E\left(c_{i, t} \mid x\right)$, where $x$ is a vector of observables. We begin with the first part. Let $c_{i, t}^{*}=0$ if $c_{i, t}=0, c_{i, t}^{*}=1$ if $c_{i, t} \in(0,1)$ and $c_{i, t}^{*}=2$ if $c_{i, t}=1$. Then,

$$
E\left(c_{i, t}^{*} \mid x\right)=F\left(x \beta_{1}\right)
$$

where $\beta_{1}$ is a vector of variable coefficients and $F($.$) is a distribution function to be chosen$ by the econometrician. In our case, we will estimate this model using the ordered probit model.

The second part of our model deals with instances where the participant chooses a positive contribution level which is less than his full endowment for that period:

$$
E\left[c_{i, t} \mid x, c_{i, t} \in(0,1)\right]=M\left(x \beta_{2}\right)
$$

\footnotetext{
${ }^{13}$ We nevertheless conducted random effects Tobit estimations as robustness checks, which we report in the Appendix to this paper. With the exception of the results from regression (2), the results of the Tobit estimates are consistent with the analysis of the two-part model, although naturally the interpretation of the results is slightly different.
} 
where $M($.$) is a distribution function. As such, the two part-model can be described as$ follows:

$$
E\left[c_{i, t} \mid x\right]=E\left[c_{i, t} \mid x, c_{i, t} \in(0,1)\right] \operatorname{Pr}\left[c_{i, t}^{*} \in(0,1) \mid x\right]=M\left(x \beta_{2}\right) F\left(x \beta_{1}\right)
$$

\subsubsection{To contribute maximally, or not at all?}

We begin by reporting the data on the estimation of the decision whether to free-ride, or to contribute the maximum amount, which we execute through a random effects ordered probit model.

Regression (3) models the probability of contributing zero or one hundred percent of one's endowment as a function of treatment dummies plus a period variable to account for learning during the session. The omitted category is the Control treatment without identity. A positive (negative) coefficient means that an increase in the value of the regression leads to an increase (decrease) in the predicted probability of moving from the lower threshold, zero contributions, to the higher threshold of full contribution. We see that with the exception of $5-1 \times$ RESTRICT, all treatment dummy coefficients are negative and highly significant, which implies we are more likely to observe full contributions in the Control treatment than in either PUBLIC or RESTRICT treatments. Focusing on the effect of fragmentation, we see that the coefficients on 5-1 in both information conditions are significantly larger than those for 6-0 and 4-2. That is, subjects in the 5-1 condition are more likely to fully contribute to the public good than players in either 6-0 and 4-2. Furthermore, the coefficients on the 6-0 and 3-3 are not statistically different in either PUBLIC or Restrict. ${ }^{14}$

Regression (4) decomposes the effect of fragmentation by looking at the behaviour of minorities and majorities. The coefficients on the main treatment interactions (which now apply to the majority group in the cases of the 5-1 and 4-2 interactions) remain

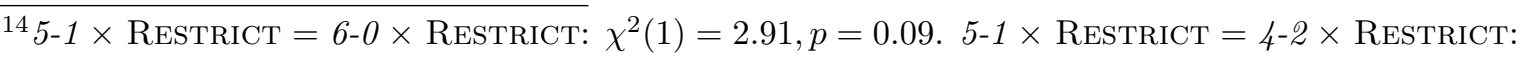
$\chi^{2}(1)=4.52, p=0.03 .5-1 \times$ Public $=6-0 \times$ Public: $\chi^{2}(1)=8.17, p<0.01 .5-1 \times$ Public $=4-2$ $\times$ Public: $\chi^{2}(1)=11.16, p<0.01 ; 6-0 \times$ Public $=3-3 \times$ Public: $\chi^{2}(1)=0.28, p=0.60 ; 6-0 \times$ RESTRICT $=3-3 \times$ RESTRICT: $\chi^{2}(1)=0.09, p=0.76$
} 


\begin{tabular}{|c|c|c|c|c|}
\hline & $(3)$ & $(4)$ & $(5)$ & $(6)$ \\
\hline 6 -0 $\times$ RESTRICTED & $\begin{array}{c}-0.50^{* * *} \\
(0.10)\end{array}$ & $\begin{array}{c}-0.50^{* * *} \\
(0.10)\end{array}$ & $\begin{array}{c}-0.56^{* * *} \\
(0.16)\end{array}$ & \\
\hline 5-1 × RESTRICTED & $\begin{array}{c}-0.33^{* * *} \\
(0.10)\end{array}$ & $\begin{array}{c}-0.27^{* * *} \\
(0.10)\end{array}$ & $\begin{array}{c}-0.52^{* * *} \\
(0.17)\end{array}$ & $\begin{array}{c}0.14 \\
(0.10)\end{array}$ \\
\hline 4-2 × RESTRICTED & $\begin{array}{c}-0.54^{* * *} \\
(0.10)\end{array}$ & $\begin{array}{c}-0.50^{* * *} \\
(0.11)\end{array}$ & $\begin{array}{c}-0.57^{* * *} \\
(0.16)\end{array}$ & $\begin{array}{l}-0.00 \\
(0.10)\end{array}$ \\
\hline 3-3 × RESTRICTED & $\begin{array}{c}-0.53^{* * *} \\
(0.10)\end{array}$ & $\begin{array}{c}-0.53^{* * *} \\
(0.10)\end{array}$ & $\begin{array}{c}-0.56^{* * *} \\
(0.16)\end{array}$ & $\begin{array}{l}-0.01 \\
(0.10)\end{array}$ \\
\hline 4-2 $\times$ RESTRICTED $\times$ Min & & $\begin{array}{l}-0.12 \\
(0.10)\end{array}$ & & \\
\hline 5-1 × RESTRICTED $\times$ Min & & $\begin{array}{c}-0.36^{* * *} \\
(0.12)\end{array}$ & & \\
\hline $6-0 \times$ PuBlic & $\begin{array}{c}-0.25^{* * *} \\
(0.10)\end{array}$ & $\begin{array}{c}-0.25^{* * *} \\
(0.10)\end{array}$ & $\begin{array}{c}0.19 \\
(0.16)\end{array}$ & $\begin{array}{c}0.35^{* * *} \\
(0.10)\end{array}$ \\
\hline $5-1 \times$ PUBLIC & $\begin{array}{c}0.01 \\
(0.10)\end{array}$ & $\begin{array}{l}-0.03 \\
(0.10)\end{array}$ & $\begin{array}{l}-0.07 \\
(0.16)\end{array}$ & $\begin{array}{c}0.58^{* * *} \\
(0.10)\end{array}$ \\
\hline $4-2 \times$ PUBLIC & $\begin{array}{c}-0.29^{* * *} \\
(0.09)\end{array}$ & $\begin{array}{c}-0.26^{* * *} \\
(0.10)\end{array}$ & $\begin{array}{l}0.30^{*} \\
(0.16)\end{array}$ & $\begin{array}{c}0.28^{* * *} \\
(0.10)\end{array}$ \\
\hline 3-3 × Public & $\begin{array}{c}-0.30^{* * *} \\
(0.09)\end{array}$ & $\begin{array}{c}-0.30^{* * *} \\
(0.09)\end{array}$ & $\begin{array}{l}0.30^{*} \\
(0.16)\end{array}$ & $\begin{array}{c}0.33^{* * *} \\
(0.10)\end{array}$ \\
\hline $4-2 \times$ PUBLIC $\times$ Min & & $\begin{array}{l}-0.08 \\
(0.08)\end{array}$ & & \\
\hline $5-1 \times$ PUBlic $\times$ Min & & $\begin{array}{l}0.25^{* *} \\
(0.11)\end{array}$ & & \\
\hline PUBLIC $\times \bar{c}_{-i, t-1}^{O}$ & & & $\begin{array}{c}0.01^{* * *} \\
(0.00)\end{array}$ & \\
\hline PUBLIC $\times \bar{c}_{-i, t-1}^{I}$ & & & $\begin{array}{l}0.01^{* * *} \\
(0.00)\end{array}$ & \\
\hline RESTRICTED $\times \bar{c}_{-i, t-1}$ & & & $\begin{array}{c}0.02^{* * *} \\
(0.00)\end{array}$ & \\
\hline Control $\times \bar{c}_{-i, t-1}$ & & & $\begin{array}{c}0.01^{* * *} \\
(0.00)\end{array}$ & \\
\hline No. of Lines & & & & $\begin{array}{l}-0.00 \\
(0.00)\end{array}$ \\
\hline Statement & & & & $\begin{array}{l}0.36^{* *} \\
(0.15)\end{array}$ \\
\hline Agreement & & & & $\begin{array}{c}-1.78^{* * *} \\
(0.29)\end{array}$ \\
\hline Period & & & $\begin{array}{c}-0.03^{* * *} \\
(0.00)\end{array}$ & $\begin{array}{c}-0.05^{* * *} \\
(0.00)\end{array}$ \\
\hline Cutoff 1 & $\begin{array}{c}-1.04^{* * *} \\
(0.07)\end{array}$ & $\begin{array}{c}-1.04^{* * *} \\
(0.07)\end{array}$ & $\begin{array}{c}-1.02^{* * *} \\
(0.16)\end{array}$ & $\begin{array}{c}-1.32^{* * *} \\
(0.12)\end{array}$ \\
\hline Cutoff 2 & $\begin{array}{c}1.02^{* * *} \\
(0.07)\end{array}$ & $\begin{array}{c}1.03^{* * *} \\
(0.07)\end{array}$ & $\begin{array}{c}1.14^{* * *} \\
(0.15)\end{array}$ & $\begin{array}{c}0.80^{* * *} \\
(0.12)\end{array}$ \\
\hline $\mathrm{N}$ & 6,840 & 6,840 & 6,840 & 6,156 \\
\hline
\end{tabular}

Sig. levels: ${ }^{* *}: 1 \%,{ }^{* *}: 5 \%,{ }^{*}: 1280$.

Table 3: Random effects ordered probit estimation of the decision to free-ride or fully contribute $(F()$.$) .$ 
virtually the same in both Public and Restricted. However, we see markedly different behaviour when we look at the minority group interactions. While the interactions of 4-2 with minority are both close to and not significantly different than zero, the same is not the case in the 5-1 treatment. While 5-1 $\times$ RESTRICTED $\times$ Min is negative and significant, $5-1 \times$ PUBLIC $\times$ Min is positive and significant. That is, the minority players in 5-1 are more likely to fully contribute than the majority if their contributions are identifiable, while the opposite is true when the only feedback about contributions is in aggregated form. This is consistent with the evidence in Figure ??. Looking at the top half of the panel, which corresponds to the 5-1 case, we see that in the PUBLIC condition there is a marked difference between the distribution of contribution levels of majority and minority. In particular, minorities have a very high percentage of maximum contributions, almost twice as much as that of the majority, but not a lot of difference in the fraction of observations recording zero contributions. In the RESTRICTED condition, we see the mirror image of that difference: the distribution of contributions of the minority has much more mass on zero contributions than the contribution distribution of the majority group.

Regression (5) considers how current contributions are affected by the behaviour of other subjects in the previous period (measured by the average contribution by a subject's in-group and out-group members in the previous period in PUBLIC: PUBLIC $\times$ $\bar{c}_{-i, t-1}^{I}$, PUBLIC $\times \bar{c}_{-i, t-1}^{O}$ and the average contribution by the other five subjects in the previous period in RESTRICTED: RESTRICTED $\left.\times \bar{c}_{-i, t-1}\right)$. We find that in all treatments, the higher the average contributions by other subjects in the previous period, the more likely it is that a subject in this period will make the maximum contribution. This effect is strongest for the RESTRICTED condition. In the PUBLIC condition, we can distinguish between the average contributions of in-group and out-group subjects, but we find no difference in the coefficients. ${ }^{15}$

\footnotetext{
${ }^{15}$ PUBLIC $\times \bar{c}_{-i, t-1}^{O}=$ PUBLIC $\times \bar{c}_{-i, t-1}^{O}: \chi^{2}(1)=0.05, p=0.83$. Breaking up the analysis by treatment and minority/majority does not change the results and would make the presentation extremely cumbersome due to the large number of regressors. These results are available from the authors upon request.
} 

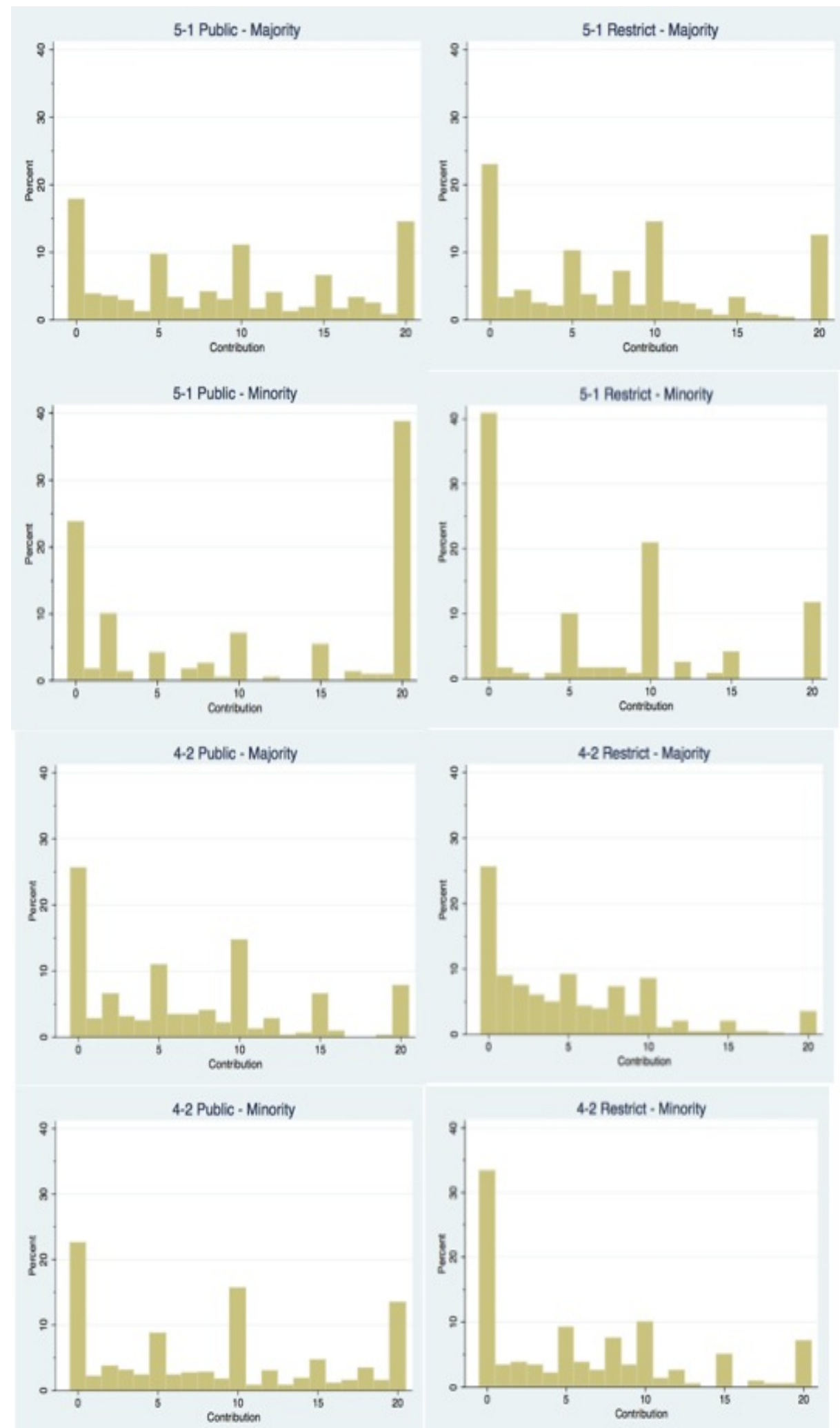

Figure 2: Distributions of contribution levels by majorities and minorities, PUBLIC and RESTRICT 
We are also interested in how the strength of affiliation may accentuate the effect of group fragmentation. To test for this, we resort to a number of different variables, based on the transcripts from the chat stage in the first stage of the experiment. We employed two independent reviewers who coded the group conversations according to the following key concepts: generic statements, expressions of agreement, which indicate strong team building; expressions of disagreement, which indicate weak team dynamics; the reviewers counted the number of times a subject asked a question during the chat stage and the number of times he obtained an answer, which may be proxies for reciprocity (Chen and Chen, 2011). ${ }^{16}$ Finally, we also included the number of lines recorded for each group, which measure the degree of involvement in the task. We aggregated those measures at the group level. Regression (6) completes the analysis by looking at strength of identity. We find the number of lines has no effect on behaviour. The coefficient on Statement is positive and significant but, surprisingly, the coefficient on Agreement is negative and significant. As such, we are unable to draw any conclusive answers from strength of identity.

\subsubsection{How much to contribute if not everything?}

We now turn to the fractional regression component of the analysis. In other words, we now focus on subjects' decision of how much to contribute, given that they did not want to neither fully-free ride nor fully contribute. Table ?? reports the output of the random effects probit estimations.

Regression (7) focuses on treatment effects using dummy variables, where Control is the omitted variable. Focusing on treatment conditions, we see a significant difference between the 5-1 $\times$ RESTRICTED condition and both 6-0 6 RESTRICTED and 4- $2 \times$ RESTRICTED, in that we are more likely to observe higher contributions in the former,

\footnotetext{
${ }^{16}$ We compared the two reviewers' coding using a measure of consistency (Cronbach's alpha) and we only incorporated variables in which the coefficient was above 0.8 . This was the case for generic statements, expressions of agreement and questions. However, the measure of consistency between coders was poor for the answer variable. As such, we decided to exclude both question and answer variables.
} 


\begin{tabular}{|c|c|c|c|c|}
\hline & $(7)$ & $(8)$ & $(9)$ & $(10)$ \\
\hline 6 -0 $\times$ RESTRICTED & $\begin{array}{c}-0.37^{* * *} \\
(0.04)\end{array}$ & $\begin{array}{c}-0.37^{* * *} \\
(0.04)\end{array}$ & $\begin{array}{c}-0.23^{* * *} \\
(0.08)\end{array}$ & \\
\hline 5-1 × RESTRICTED & $\begin{array}{c}-0.20^{* * *} \\
(0.03)\end{array}$ & $\begin{array}{c}-0.21^{* * *} \\
(0.04)\end{array}$ & $\begin{array}{c}-0.17^{* *} \\
(0.08)\end{array}$ & $\begin{array}{c}0.17^{* * *} \\
(0.04)\end{array}$ \\
\hline 4-2 2 RESTRICTED & $\begin{array}{c}-0.39^{* * *} \\
(0.04)\end{array}$ & $\begin{array}{c}-0.46^{* * *} \\
(0.04)\end{array}$ & $\begin{array}{c}-0.27^{* * *} \\
(0.08)\end{array}$ & $\begin{array}{l}-0.00 \\
(0.04)\end{array}$ \\
\hline 3-3 × RESTRICTED & $\begin{array}{c}-0.39^{* * *} \\
(0.04)\end{array}$ & $\begin{array}{c}-0.39^{* * *} \\
(0.04)\end{array}$ & $\begin{array}{c}-0.24^{* * *} \\
(0.08)\end{array}$ & $\begin{array}{l}-0.01 \\
(0.03)\end{array}$ \\
\hline 4-2 $\times$ RESTRICTED $\times$ Min & & $\begin{array}{c}0.23^{* * *} \\
(0.05)\end{array}$ & & \\
\hline $5-1 \times$ RESTRICTED $\times$ Min & & $\begin{array}{c}0.10 \\
(0.36)\end{array}$ & & \\
\hline 6-0 $\times$ PUBLIC & $\begin{array}{c}-0.25^{* * *} \\
(0.04)\end{array}$ & $\begin{array}{c}-0.25^{* * *} \\
(0.04)\end{array}$ & $\begin{array}{c}0.05 \\
(0.08)\end{array}$ & $\begin{array}{c}0.15^{* * *} \\
(0.04)\end{array}$ \\
\hline $5-1 \times$ PUBLIC & $\begin{array}{l}-0.07^{*} \\
(0.04)\end{array}$ & $\begin{array}{l}-0.03 \\
(0.04)\end{array}$ & $\begin{array}{l}0.18^{* *} \\
(0.06)\end{array}$ & $\begin{array}{c}0.34^{* * *} \\
(0.04)\end{array}$ \\
\hline 4-2 $\times$ PUBLIC & $\begin{array}{c}-0.11^{* * *} \\
(0.03)\end{array}$ & $\begin{array}{c}-0.14^{* * *} \\
(0.04)\end{array}$ & $\begin{array}{c}0.23^{* * *} \\
(0.08)\end{array}$ & $\begin{array}{c}0.29^{* * *} \\
(0.04)\end{array}$ \\
\hline 3-3 × PUBLIC & $\begin{array}{c}-0.15^{* * *} \\
(0.03)\end{array}$ & $\begin{array}{c}-0.15^{* * *} \\
(0.03)\end{array}$ & $\begin{array}{c}0.22^{* * *} \\
(0.08)\end{array}$ & $\begin{array}{c}0.27^{* * *} \\
(0.04)\end{array}$ \\
\hline 4-2 $2 \times$ PUBLIC $\times$ Min & & $\begin{array}{l}0.08 \\
(0.05)\end{array}$ & & \\
\hline $5-1 \times$ PUBLIC $\times$ Min & & $\begin{array}{c}-0.28^{* * *} \\
(0.08)\end{array}$ & & \\
\hline PUBLIC $\times \bar{c}_{-i, t-1}^{O}$ & & & $\begin{array}{c}0.003^{* * *} \\
(0.00)\end{array}$ & \\
\hline PUBLIC $\times \bar{c}_{-i, t-1}^{I}$ & & & $\begin{array}{c}0.01^{* * *} \\
(0.00)\end{array}$ & \\
\hline RESTRICTED $\times \bar{c}_{-i, t-1}$ & & & $\begin{array}{c}0.01^{* * *} \\
(0.00)\end{array}$ & \\
\hline Control $\times \bar{c}_{-i, t-1}$ & & & $\begin{array}{c}0.02^{* * *} \\
(0.00)\end{array}$ & \\
\hline No. of Lines & & & & $\begin{array}{c}0.00 \\
(0.00)\end{array}$ \\
\hline Statement & & & & $\begin{array}{c}0.22^{* * *} \\
(0.07)\end{array}$ \\
\hline Agreement & & & & $\begin{array}{c}-0.59^{* * *} \\
(0.15)\end{array}$ \\
\hline Period & & & $\begin{array}{c}-0.01^{* * *} \\
(0.00)\end{array}$ & $\begin{array}{c}-0.02^{* * *} \\
(0.0)\end{array}$ \\
\hline Constant & $\begin{array}{c}-0.06^{* *} \\
(0.02) \\
\end{array}$ & $\begin{array}{c}-0.06^{* *} \\
(0.02) \\
\end{array}$ & $\begin{array}{c}-0.58^{* * *} \\
(0.08)\end{array}$ & $\begin{array}{c}-0.27^{* * *} \\
(0.06)\end{array}$ \\
\hline $\mathrm{N}$ & 4,709 & 4,709 & 4,443 & 4,160 \\
\hline
\end{tabular}

Sig. levels: ${ }^{* * *}: 1 \%,{ }^{* *}: 5 \%,{ }^{*}: 10 \%$.

Table 4: Random effects probit estimates of how much to contribute to the public good. $(G()$.$) .$ 
than in either of the latter two. On the other hand, the same comparisons in the Public condition only yield significant differences when comparing 6-0 to 5-1. We find no significant differences between the 6-0 and 3-3 conditions in RESTRICTED, but a significant difference in PuBLIC. ${ }^{17}$

Regression (8) augments (7) by accounting for minorities in the 4-2 and 5-1 conditions. Contrary to the analysis of full/no-contributions, We find non-significant coefficients on 5-1 $\times$ Restricted $\times$ Min and $4-2 \times$ PUblic $\times$ Min. In other words, conditional on contributing a positive amount, 2-strong minorities will contribute more on average than their majority counterparts when feedback about contributions is restricted to the aggregate, but not when individual-level contributions are known. In the 5-1 case, the role of information is reversed: there are no differences in average contributions between minority and majority in RESTRICTED, while in PUBLIC the minority players contribute on average less than the majority.

Regression (9) considers the effect of past average contribution levels on current contributions. Higher past average contributions by the other subjects imply a higher average contribution today. In the case of PUBLIC, the effect is larger for in-group members than for out-group members (PUBLIC $\times \bar{c}_{-i, t-1}^{O}=$ PUBLIC $\times \bar{c}_{-i, t-1}^{O}: \chi^{2}(1)=$ $26.72, p<0.01$.) The basic findings of Regression (1) remain unchanged.

Regression (10) considers the effect of strength of identity. We again find that the amount of communication is a poor predictor of behaviour, and that while generic statements are positively correlated with average contributions, expressions of agreement are negatively correlated with average contributions.

Conducting a similar analysis using the Tobit model yields very similar results, with an important exception - see Appendix B. Because the Tobit model does not formally account for different behavioural responses at the extremes of the contribution distribution, it is not capable of identifying how in some cases fragmentation positively affects

\footnotetext{
17 5-1 $\times$ RESTRICTED $=6-0 \times$ RESTRICTED: $\chi^{2}(1)=24.05, p<0.01 ; 5-1 \times$ RESTRICTED $=4$ - 2 $\times$ Restricted: $\chi^{2}(1)=29.61, p<0.01 ; 5-1 \times$ Public $=6$ - $0 \times$ Public: $\chi^{2}(1)=18.77, p<0.01$; $5-1 \times$ Public $=4-2 \times$ Public: $\chi^{2}(1)=0.97, p=0.32 ; 6-0 \times$ Restricted $=3-3 \times$ Restricted: $\chi^{2}(1)=0.21, p=0.65 ; 6$ - $0 \times$ Public $=3$ - $3 \times$ Public: $\chi^{2}(1)=7.69, p<0.01$.
} 
the likelihood of fully contributing to the public good, while having the opposite effect on subjects who only contribute a fraction of their endowment.

\section{Discussion}

Social fragmentation, along ethnic, linguistic or religious lines has been identified as the cause for low public good provision in settings as diverse as U.S cities and rural Pakistan. However, the existing research on social fragmentation has been unable to identify the underlying mechanism which causes societies with higher levels of fragmentation to under-perform. Is this caused by discriminatory preferences based on a sense of affiliation towards a social group, or is it instead caused by the fact that different social groups may prefer different types of public goods?

The present paper seeks to understand the extent to which the former explanation is at the heart of this problem. We conducted an experiment where two artificial social groups could contribute to a single public good. Keeping the total number of players constant, we systematically varied the relative size of the two groups as a proxy of social fragmentation. In one extreme, we minimised fragmentation by having all players belong to the same group. In the other extreme, we maximised fragmentation by having half of players belonged to one group, while the other half belonged to the other group.

The evidence we report to some extent qualifies the results from the existing literature. In the context of our experiment, in the absence of outsiders a sense of identity is irrelevant with respect to the contributions to the public good. Indeed, our data found that the average contribution by subjects in games where everyone was from the same group were no different from those subjects who played the same game in an identityfree condition. This suggests that one's sense of belonging to a particular group is a function of how salient that group is. Once everyone is a member of the same group, membership of that group ceases to have meaning, and this is reflected in the behaviour in the experiment.

However, our data partially replicates the pattern shown by the empirical literature: 
so long as there is some degree of social fragmentation, then increasing social fragmentation decreases public good provision. However, socially homogeneous populations do not exhibit higher contributions than maximally fragmented populations. This suggests that there is an optimal level of diversity in a population. The mechanism for this is simple: the fact that different social groups exist triggers a meaning to belonging to a group, and thus a utility from membership. This in turn creates the willingness to contribute to the public good, as it will benefit one's in-group members. So long as the positive in-group biases dominate the negative out-group biases, then the net effect is higher public good provision.

However, the econometric analysis of the distributional effects of fragmentation paints a more complex picture, once we look beyond simple average contribution levels. We observe that the jump in average contributions when we move from no social fragmentation to minimal fragmentation is driven by a higher likelihood of contributing the maximal amount. This suggests that social identity concerns, as opposed to self interest, are the driving forces in behaviour in our experiment.

When we compare the behaviour of majorities to that of minorities, we find that the effect of fragmentation is highly dependent on the type of feedback subjects received about others. The type of feedback we provided to subjects in different treatments proxies the degree of visibility of the actions taken by members of a particular social group. In one condition, subjects could observe all the individual contributions in a given period, while in another condition, subjects only knew the total contribution by the other five subjects in that period. A possible interpretation of our information conditions is that the former mimics the conditions one experiences in a small community, where the behaviour of every individual is very easy to monitor. The latter proxies the conditions one experiences in, say, a large city - there, one can only observe aggregate levels of public good contribution, but not what each individual contributes.

The interaction of informational condition with fragmentation reveals different behavioural responses by minority members, particularly in the condition where the minority consisted of one individual. When individual feedback is available, minority members 
are more likely to fully contribute to the public good and less likely to free-ride. However, conditional on contributing a fraction of their endowment, they contribute on average less than the majority group members. When individual information is unavailable, we find almost the opposite effect: minority players are more likely to free-ride and less likely to fully contribute. If contributing some of their endowment, they are indistinguishable from majority members.

This suggests that the capacity to single out individuals can lead to them conforming to a particular norm, even under the strict anonymity conditions afforded by the lab. In short, the social context in which people contribute towards a public good is an important determinant of the effect of social fragmentation. Our finding that visible minorities display higher contribution rates also suggests, perhaps counter-intuitively, that social integration may be easier in (or more beneficial to) smaller communities rather than large cities.

In this sense, it is perhaps appropriate to return to the quote with which we began the paper. Putnam (2007) argues that while beneficial in the long run, in the short-run social diversity brings about a generalised decline in trust, not only towards outsiders but also to those from one's social group. This decline is reflected in lower civic participation and lower levels of cooperation. Our findings suggest that his findings are unlikely to be explained by social identity arguments. Not only are our highest public good contribution levels recorded in a treatment with social heterogeneity, but they are highest when the actions by members of the minority group are visible. The reason for the discrepancy could lie in factors outside the scope of this study: the role of social networks (who you know and who they know) and how they interact with labour market conditions (Constant and Zimmermann, 2005; Pendakur and Pendakur, 2005). We leave such issues for future research. 


\section{References}

[1] Akerlof, G.A., and Kranton, R.E. 2000. Economics and identity. Quarterly Journal of Economics 115 (3), 715-753.

[2] Alesina, A., Baqir, R., and Easterly, W. 1999. Public goods and ethnic divisions. Quarterly Journal of Economics 114 (4), 1243-1284.

[3] Alesina, A., Devleeschauwer, A., Easterly, W., Kurlat, S., and Wacziarg, R. 2003. Fractionalization. Journal of Economic Growth 8 (2), 155-194.

[4] Alesina, A., and La Ferrara, E. 2000. Participation in heterogeneous communities $115(3), 715-753$.

[5] Alesina, A., and La Ferrara, E. 2005. Ethnic diversity and economic performance. Journal of Economic Literature 43 (3), 762-800.

[6] Allport, G. 1954. The nature of prejudice. Cambrige, Mass: Addison-Wesley

[7] Anderson, S. 2011. Caste as an impediment to trade. American Economic Journal: Applied Economics 3, 239-263.

[8] Bowles, S., and Gintis, S. 2004. Persistent parochialism: trust and exclusion in ethnic networks. Journal of Economic Behavior and Organization 55 (1), 1-23.

[9] Brewer, M.B. The social self: on being the same and different at the same time. Personality and Social Psychology Bulletin 17 (5), 475-482.

[10] Brown-Kruse, J., and Hummels, D.L. 1993. Gender effects in laboratory public goods contribution: do individulas put their money where their mouth is? Journal of Economic Behavior and Organization 22 (3), 255-267

[11] Cadsby, C.B., and Maynes, E. 1998. Gender and free riding in a threshold public goods game: experimental evidence. Journal of Economic Behavior and Organization 34 (4), 603-620. 
[12] Charness, G., Rigotti, L., and Rustichini, A. 2007. Individual behavior and group membership. American Economic Review 97 (4), 1340-1352.

[13] Chen, Y., and Li, S.X. 2009. Group identity and social preferences. American Economic Review 99 (1), 431-457.

[14] Chen, Y., and Chen, R. 2011. The potencial of social identity for equilibrium selection. American Economic Review 101 (6), 2652-2689.

[15] Constant, A.F., and Zimmermann, K.F. 2008. Measuring ethnic identity and its impact on economic behavior. Journal of the European Economic Association 6, 424433.

[16] Cox, T.H., Lobel, S.A., and McLeod, P.L. 1991. Effects of ethnic group cultural differences on cooperative and competitive behavior on a group task. Academy of Management Journal 34 (4), 827-847.

[17] Croson, R., Marks, M., and Snyder, J. 2008. Groups work for women: gender and group identity in the provision of public goods. Negotiation Journal 24 (4), 411-427.

[18] Dana, J., Weber, R. and J. X. Kuang. 2007. Exploiting Moral Wriggle Room: Behavior Inconsistent with a Preference for Fair Outcomes. Economic Theory, 33, $67-80$.

[19] Devereux, J., and Fishe, R.P.H. 1993. An economic analysis of group lending in developing countries. Developing Economies 31 (1), 102-121.

[20] Easterly, W., and Levine, R. 1997. Africa's growth tragedy: Africa's growth tragedy: policies and ethnic divisions. Quarterly Journal of Economics 112 (4), 1203-1250.

[21] Eckel, C.C., and Grossman, P.J. 2005. Managing diversity by creating team identity. Journal of Economic Behavior and Organization ??, 371-392.

[22] Espinosa, J.A., and Garza, R.T. 1985. Social group salience and interethnic cooperation. Journal of Experimental Social Psychology 21 (4), 380-392. 
[23] Fehr, E., and Hoff, K. 2011. Introduction: Tastes, castes and culture: The influence of society on preferences. Economic Journal 121, F396-412.

[24] Galeotti, F. and Zizzo, D.J. 2012. Trust and Trustworthiness with Singleton Groups. University of East Anglia Centre for Behavioural and Experimental Social Science Working Paper 12-03.

[25] Goette, L, Huffman, D., and Meier, S. 2006. The impact of group membership on cooperation and norm enforcement: evidence using random assignment to real social groups. American Economic Review 96 (2), 202-216.

[26] Habyarimana, J., Humphreys, M., Posner, D.N., and Weinstein, J. 2007. Why does ethnic diversity undermine public good provision? American Political Science Review 101 (4), 709-725.

[27] Haslam, S.A. 2004. Psychology in Organizations - The Social Identity Approach 2nd edition London: Sage Publications Ltd

[28] Karlan, D.S. 2007. Social connections and group banking. Economic Journal 117, F52-F84.

[29] Khwaja, A.I. 2009. Can good projects succeed in bad communities? Journal of Public Economics 93 (7-8), 899-916.

[30] Kramer, R.M., and Brewer, M.B. 1984. Effects of group identity on resource use in a simulated commons' dilemma. Journal of Personality and Social Psychology 46 (5), 1044-1057.

[31] La Ferrara, E. 2003. Kin groups and reciprocity: a model of credit transactions in Ghana. American Economic Review 93 (5), 1730-1751.

[32] La Porta, R., Lopez-de-Silanes, F., Schleifer, A., and Vishny, R.W. 1999. The quality of government. Journal of Law, Economics and Organization 15 (1), 222-279. 
[33] Luttmer, E.F.P. 2001. Group loyalty and the taste for redistribution. Journal of Political Economy 109, 500-528.

[34] Miguel, E., and Gugerty, M.K. 2005. Ethnic diversity, social sanctions and public goods in Kenya. Journal of Public Economics 89 (11-12), 2325-2368.

[35] McLeish, K.N., and Oxoby, R.J. 2007. Identity, cooperation and punishment. IZA Discussion Paper No. 2572.

[36] Pendakur, K., and Pendakur, R. 2005. Ethnic identity and the labour market. Unpublished manuscript, Simon Fraser University.

[37] Poterba, J.M. 1998. Demographic change, intergenerational linkages, and public education. American Economic Review 88, 315-320.

[38] Putnam, R.D. 2007. E pluribus unum: diversity and community in the twenty-first century - the 2006 Johan Skytte Prize. Scandinavian Political Studies 30 (2), 137-174.

[39] Shayo, M. 2009. A model of social identity with an application to political economy: nation, class and redistribution. American Political Science Review 103 (2), 147-174.

[40] Sherif, M., Harvey, O.J., White, B.J., Hood, W.R., and Sherif, C.W. 1988. The robbers' cave experiment: Intergroup conflict and cooperation. Norman: Oklahoma: University Book Exchange

[41] Solow, J.L., and Kirkwood, N. 2002. Group identity and gender in public goods experiments. Journal of Economic Behavior and Organization 48 (4), 403-412.

[42] Tajfel, H. 1970. Aspects of national and ethnic loyalty. Social Science Information $9(3), 119-144$.

[43] Tajfel, H., Billig, M.G., Bundy, R.P., and Flament, C. 1971. Social categorization in intergroup behavior. European Journal of Social Psychology 1 (2), 149-178. 
[44] Tajfel, H., and Turner, J.C. 1979. An integrative theory of intergroup conflict. in Austin, W.G. and Worchel, S. (eds) The social psychology of intergroup relations. Monterey, CA: Brooks/Cole

[45] US Census Bureau 2009. An Older and More Diverse Nation by Midcentury.

[46] Wit, A.P., and Wilke, H.A.M. 1992. The effect of social categorization on cooperation in three types of social dilemmas. Journal of Economic Psychology 13 (1), $135-151$.

\section{Appendix A: Instruction Sets}

\section{Instruction Set}

Welcome to our experiment. Please remain silent during the course of the experiment. If you have any questions, please raise your hand. You will now take part in a decisionmaking experiment. The amount you will receive for participating will depend on your decisions and the decisions of other participants. There will be 2 parts to this experiment. Before each part of the experiment begins, you will receive a set of instructions explaining the details of that particular part.

Once you complete all the decisions in a given part, we will move to the next part of the experiment. You will only receive information about the outcome of your choices at the end of the experiment. To keep track of your choices, we will provide you with a decision form. Your payoff in this experiment will be equal to the sum of payoffs in each of the individual parts. The payoffs throughout the experiment will be denominated in Experimental Currency Units (ECU); 1 ECU is worth 20 cents. Once the experiment ends, your payoff will be calculated and you will receive your payment in cash.

\section{Part 1 (All Treatments)}


In this part we will show you five pairs of paintings by two artists. For each pair of paintings, you must choose the one you prefer. Once everyone makes their five choices, we will divide participants into two groups according to which artist they preferred.

Once you have been allocated to one of the groups, we will show you a further two paintings. Your task will be to identify which artist painted which painting. You will be allowed to confer with your fellow group members in order to determine the answer to the two questions. To this effect, you will have access to a chat programme, through which you can offer help or get help from your fellow group members.

Messages you post in the chat box will only be visible to members of your own group. You will not be able to see the messages posted by members of the other group and viceversa. You will be able to communicate with your fellow group members for 10 minutes before submitting your answers. You are free to post how many messages you like. There are only two restrictions on messages: you may not post messages which identify yourself (e.g. age, gender, location etc.) and you may not use offensive language. For each correct answer you will earn 10 ECU. Once everyone submits their answers, the experiment will move to the second part. You will only be informed of your payoff in this part of the experiment at the very end of the session.

\section{Part 2 (PG Treatment) - only seen after the end of Part 1}

In this part of the experiment you will be matched with five other participants. You will be interacting with the same five participants until the end of the experiment.

There will be 20 rounds in this part of the experiment. At the beginning of each round, each participant will receive 20 ECUs. We will call this your endowment. Your task in each round is to decide how to use your endowment. You must decide how many ECUs you want to contribute to a project and how many you want to keep for yourself. The consequences of your decision are explained in detail below. Your payoff is given by the following formula:

Your Payoff $=(20$ ECU - Your Contribution $)+\left(0.4^{*}\right.$ Total Contribution $)$ 
This formula implies that your payoff in every round is based on two parts:

1. The ECUs you kept for yourself: (20 ECU - Your contribution.)

2. The income from the project, which is $40 \%$ of the total contribution from you and from the other five participants.

The payoff of each of the six participants is calculated in the same way. This means that the income from the project is the same for everyone.

To fix ideas, let's consider a few numerical examples. Suppose that the total contribution to the project is 60 ECU. In this case, each of the six participants receives an income from the project of $0.4^{*} 60=24 \mathrm{ECU}$. If instead the total contribution to the project is $9 \mathrm{ECU}$, then each of the six participants will receive an income of $0.4^{*} 9=3.6$ ECU from the project.

Each ECU you keep to yourself raises your payoff by 1 ECU. Each ECU you contribute to the project raises the total contribution to the project by 1 ECU and causes your income from the project to rise by $0.4^{*} 1=0.4 \mathrm{ECU}$. The income of the other five participants will also rise by $0.4 \mathrm{ECU}$, so that the total income of the six participants from the project will go up by 2.4 ECU. Your contribution to the project therefore also raises the income of the other participants. Conversely, contributions to the project by other participants also raise your income; for each ECU contributed by another participant, you earn $0.4^{*} 1=0.4$ ECU.

Remember that ECUs earned in one round do NOT carry over to subsequent rounds. You will start every round with the same endowment of 20 ECUs.

Once all participants have made their decisions, you will be informed about your decision, the decision of each participant, the total amount of ECUs contributed to the project and your payoff. You will also know whether each person with whom you are playing belongs to either the Kandinsky or the Klee group, but not their exact identity. To this effect, the computer will scramble the order in which the other participants are listed when individual contributions are shown at the end of every round.

Once the 20th round is over, the experiment will be over. The computer will select 
two rounds at random. Your payoff in those two rounds plus the payoff from part 1 will determine your total earnings in the session.

\section{Part 2 (PG+CG: 3-3 Treatment) - only seen after the end of Part 1}

In this part of the experiment you will be matched with five other participants. You will be interacting with the same five participants until the end of the experiment. There will be 20 rounds in this part of the experiment. At the beginning of each round, each participant will receive 20 ECUs. We will call this your endowment. Your task in each round is to decide how to use your endowment.

You must decide how many ECUs you want to contribute to a public project, which is available to all six participants, how much to contribute to a project which is only available to people of your own group (Klee only if you are a member of the Klee group; Kandinsky only if you are a member of the Kandinsky group) and how many ECU you want to keep for yourself. The consequences of your decision are explained in detail below. Your payoff is given by the following formula:

Your Payoff $=20 \mathrm{ECU}+\left(0.4^{*}\right.$ Total Contribution to the Public Project - Your Contribution to the Public Project $)+\left(0.8^{*}\right.$ Total Contribution to the Group Project Your Contribution to the Group Project)

This formula implies that your payoff in every round is based on three parts:

1. The ECUs you kept for yourself: (20 ECU - Your contribution).

2. The income from the public project, which is $40 \%$ of the total contribution from you and from the other five participants.

3. The income from the group project, which is $80 \%$ of the total contribution from you and from the other two members of your group (Klee/Kandinsky only).

To fix ideas, lets consider a few numerical examples. 
Suppose that each of the six participants contributes 10 ECU to the public project and 0 ECU to their own groups project. This means the total contribution to the public project is $60 \mathrm{ECU}$ and the total contribution to your group project is $0 \mathrm{ECU}$. In this case, the income from the public project is $0.4 * 60=24$ ECU to each of the six participants, while the income from your groups project (only payable to your groups members) is 0 ECU.

Suppose instead that each of the six participants contributes 0 ECU to the public project and 10 ECU to their own groups project. This means the total contribution to the public project is $0 \mathrm{ECU}$ and the total contribution to your group project is $30 \mathrm{ECU}$. In this case, the income from the public project is 0 ECU to each of the six participants, while the income from your groups project (only payable to your groups members) is $0.8^{*} 30=24$ ECU.

Each ECU you keep to yourself raises your payoff by 1 ECU. Each ECU you contribute to the public project raises the total contribution to the project by 1 ECU and causes your income from the public project to rise by $0.4^{*} 1=0.4 \mathrm{ECU}$. The income of the other five participants will also rise by $0.4 \mathrm{ECU}$, so that the total income of the six participants from the public project will go up by 2.4 ECU. Your contribution to the project therefore also raises the income of everyone else.

Each ECU you contribute to the group project raises the total contribution to the group project by $1 \mathrm{ECU}$ and causes your income from the project to rise by $0.8^{*} 1=0.8$ ECU. The income of your other group members will also rise by $0.8 \mathrm{ECU}$, so that the total income of the three group members from the group project will go up by 2.4 ECU. Your contribution to the group project therefore also raises the income of your fellow group members, but not the income of non-group members.

In other words, 1 ECU invested in the public project yields a total benefit of 2.4 ECU to the six participants. 1 ECU invested in your group project yields a total benefit of $2.4 \mathrm{ECU}$ to the three members of your group only.

Remember that ECUs earned in one round do NOT carry over to subsequent rounds. You will start every round with the same endowment of 20 ECUs. 
Once all participants have made their decisions, you will be informed about your decision, the decision of each participant, the total amount of ECUs contributed to the public and group projects and your payoff. You will also know whether each person with whom you are playing belongs to either the Kandinsky or the Klee group, but not their exact identity. To this effect, the computer will scramble the order in which the other participants are listed when individual contributions are shown at the end of every round. Once the 20th round is over, the experiment will be over. The computer will select two rounds at random. Your payoff in those two rounds plus the payoff from part 1 will determine your total earnings in the session.

\section{Appendix B: Proofs}

Proposition 1: In the $n$-player VCM game, where each player $i$ contributes $x_{i}$ towards a public good and receives a monetary payoff $\pi_{i}$ such that $\pi_{i}:=y-x_{i}+a \sum_{j=1}^{n} x_{j}$ and has social preferences $u_{i}\left(\pi_{i}, \bar{\pi}_{-i}^{I}, \bar{\pi}_{-i}^{O}\right)=\left(1-\alpha_{i}^{I}(S)-\alpha_{i}^{O}(S)\right) \pi_{i}+\alpha_{i}^{I}(S) \bar{\pi}_{-i}^{I}+\alpha_{i}^{O}(S) \bar{\pi}_{-i}^{O}$ where $\alpha_{i}^{I}(S), \alpha_{i}^{O}(S)$ are biases and $\bar{\pi}_{-i}^{I}$ and $\bar{\pi}_{-i}^{O}$ are the average payoff of player i's ingroup members and out-group members, for a given degree of social fragmentation, $S$, it may have an equilibrium with positive contributions.

Proof: Throughout our analysis we will only consider symmetric equilibria, in that all members of the same group make the same contribution in equilibrium. To prove the existence of an equilibrium, we check To prove the existence of an equilibrium, we check $\frac{\partial^{2} u_{i}}{\partial x_{i} \partial x_{j}}$. For a given $S$, we have a symmetric game. ${ }^{18}$ Given the utility function we know that $\frac{\partial u_{i}}{\partial x_{i}}=a-\left(1-\alpha^{I}(S)-\alpha^{O}(S)\right)$. Therefore $\frac{\partial^{2} U_{i}}{\partial x_{i} \partial x_{j}}=0$. Using Topkis (1998), we know that an equilibrium exists. Further, we know that an equilibrium with positive contributions exists as long as $\frac{\partial U_{i}}{\partial x_{i}} \geq 0$ which is true as long as $a \geq 1-\alpha^{I}(S)-\alpha^{O}(S)$.

Proposition 2: In the n-player VCM game with social preferences: (i) An increase

\footnotetext{
${ }^{18}$ At this point we could, as Chen and Chen (2009) do for the minimum-effort game, use the symmetric properties of this game to calculate the optimal threshold $a$ which enables full cooperation for a given level of social fragmentation. However, our focus here is how equilibrium contributions change as a function of $S$.
} 
in social fragmentation will lead to a rise in public good contributions if the positive in-group bias grows faster than the negative out-group bias and vice-versa.

(ii) In the case where there are two sub-groups of unequal size, the majority group will contribute more than the minority group if the majority cares more about its in-group members and is less discriminatory towards out-group members than the minority.

Proof: In particular, we are interested in how the contribution of the players change as $S$ changes. Checking for the cross derivative, $\frac{\partial^{2} U_{i}}{\partial S \partial x_{i}}=\left(\alpha^{O \prime}(S)+\alpha^{I \prime}(S)\right) \cdot \frac{\partial^{2} u_{i}}{\partial S \partial x_{i}} \leq 0$ if $\left(\alpha^{O \prime}(S)+\alpha^{I \prime}(S)\right) \leq 0$. In which case, the game is one with strategic substitutes, and as $S$ increases the $x^{*}$ will decrease.

Finally, we tackle the third part of the proposition, where we establish the conditions under which the majority contributes more than the minority (or vice-versa). First consider two players, each of whom is a members a group and where the two groups are of different sizes. Let player $i$ be a member of the majority, and $x_{i}(S)$ be his contribution to the public good, where $S>1 / 2$. Let player $j$ be a minority member and $x_{j}(S)$ be his contribution, where $(1-S)<1 / 2$.

In order for player $i$ to have a higher contribution in equlibrium than player $j$, his marginal benefit from contributing to the public good must be higher than player $j$ 's. In other words, $\frac{\partial U_{i}}{\partial x_{i}}>\frac{\partial U_{j}}{\partial x_{j}} \Longleftrightarrow a-\left(1-\alpha^{I}(S)-\alpha^{O}(S)\right)>a-\left(1-\alpha^{I}(1-S)-\alpha^{O}(1-S)\right)$. Which is equivalent to $\alpha^{I}(S)+\alpha^{O}(S)>\alpha^{I}(1-S)+\alpha^{O}(1-S)$.

\section{Appendix C: Alternative Econometric Specifications}

As discussed in section ?? of the paper, we wish to conduct the econometric analysis of the contribution decisions by subjects in our experiments in a way that accounts for the particular nature of our data. In particular, we wish to account for the fact that the strategy space is truncated below by zero and truncated above by the total amount endowed to subjects in each period, 20. Here we present the results from the alternative econometric specification to the two-part model discussed in the paper, which consisted of a random-effects Tobit estimation. The dependent variable was the fraction of the 
endowment that a subject in a given period contributed to the public good.

Regression (1) looks at basic treatment effects. We confirm the finding that contributions in the 5-1 treatment were significantly higher than in both 6-0 and 4-2. In particular, we find a significant difference between 5-1 and 4-2 in the PUBLIC condition, something we had not found in the fractional part of the two-part model. We also do not find a significant difference in the coefficients of 6-0 and 3-3 in either PUBLIC or RESTRICTED conditions. ${ }^{19}$

Extending the analysis to consider minority and majority effects, we find no significant difference between minorities and majorities, with the exception of 4 - $2 \times \mathrm{RE}$ STRICTED $\times \operatorname{Min}(p=0.051)$. The difference is likely due to the fact that the tobit model does not separate behaviour at the extremes of the distribution - our two-part model indeed found contrasting effects when analysing behaviour in the extremes of the distribution and when looking at behaviour where $0<c_{i, t}<1$. When looking at how individuals respond to past contributions in regression (3), as well as strength of identity in regression (4), we again find similar results to our two-part model.

\footnotetext{
${ }^{19} 5$ - $1 \times$ REstricted $=6$-0 0 RESTRICTED: $\chi^{2}(1)=7.94, p<0.01 ; 5-1 \times$ RESTRICTED $=4$ - $2 \times$ Restricted: $\chi^{2}(1)=10.51, p<0.01 ; 5-1 \times$ Public $=6-0 \times$ Public: $\chi^{2}(1)=12.51, p<0.01$; $5-1 \times$ Public $=4-2 \times$ Public: $\chi^{2}(1)=8.34, p<0.01 ; 6-0 \times$ Restricted $=3-3 \times$ Restricted: $\chi^{2}(1)=0.20, p=0.65 ; 6-0 \times$ Public $=3-3 \times$ Public: $\chi^{2}(1)=0.07, p=0.79$.
} 


\begin{tabular}{|c|c|c|c|c|}
\hline & $(1)$ & $(2)$ & $(3)$ & $(4)$ \\
\hline 6-0 $\times$ RESTRICTED & $\begin{array}{c}-0.21^{* * *} \\
(0.03)\end{array}$ & $\begin{array}{c}-0.21^{* * *} \\
(0.03)\end{array}$ & $\begin{array}{c}-0.14^{* * *} \\
(0.04)\end{array}$ & \\
\hline 5-1 × RESTRICTED & $\begin{array}{c}-0.12^{* * *} \\
(0.03)\end{array}$ & $\begin{array}{c}-0.11^{* * *} \\
(0.03)\end{array}$ & $\begin{array}{c}-0.09^{* *} \\
(0.04)\end{array}$ & $\begin{array}{l}1.19^{* *} \\
(0.51)\end{array}$ \\
\hline 4-2 2 RESTRICTED & $\begin{array}{c}-0.22^{* * *} \\
(0.03)\end{array}$ & $\begin{array}{c}-0.24^{* * *} \\
(0.03)\end{array}$ & $\begin{array}{c}-0.14^{* * *} \\
(0.04)\end{array}$ & $\begin{array}{l}-0.30 \\
(0.51)\end{array}$ \\
\hline 3-3 × RESTRICTED & $\begin{array}{c}-0.22^{* * *} \\
(0.03)\end{array}$ & $\begin{array}{c}-0.22^{* * *} \\
(0.03)\end{array}$ & $\begin{array}{c}-0.14^{* * *} \\
(0.04)\end{array}$ & $\begin{array}{l}-0.53 \\
(0.51)\end{array}$ \\
\hline 4-2 $\times$ RESTRICTED $\times$ Min & & $\begin{array}{l}0.05^{*} \\
(0.02)\end{array}$ & & \\
\hline $5-1 \times$ RESTRICTED $\times$ Min & & $\begin{array}{l}-0.05 \\
(0.03)\end{array}$ & & \\
\hline 6-0 $\times$ PUBLIC & $\begin{array}{c}-0.11^{* * *} \\
(0.03)\end{array}$ & $\begin{array}{c}-0.11^{* * *} \\
(0.03)\end{array}$ & $\begin{array}{l}-0.03 \\
(0.04)\end{array}$ & $\begin{array}{c}1.34^{* * *} \\
(0.50)\end{array}$ \\
\hline $5-1 \times$ PUBLIC & $\begin{array}{l}-0.01 \\
(0.03)\end{array}$ & $\begin{array}{l}-0.01 \\
(0.03)\end{array}$ & $\begin{array}{c}0.04 \\
(0.04)\end{array}$ & $\begin{array}{c}2.65^{* * *} \\
(0.51)\end{array}$ \\
\hline 4-2 2 PUBLIC & $\begin{array}{c}-0.09^{* * *} \\
(0.03)\end{array}$ & $\begin{array}{c}-0.09^{* * *} \\
(0.03)\end{array}$ & $\begin{array}{l}-0.01 \\
(0.04)\end{array}$ & $\begin{array}{c}2.11^{* * *} \\
(0.48)\end{array}$ \\
\hline 3-3 × PUBLIC & $\begin{array}{c}-0.11^{* * *} \\
(0.03)\end{array}$ & $\begin{array}{c}-0.11^{* * *} \\
(0.03)\end{array}$ & $\begin{array}{l}-0.01 \\
(0.04)\end{array}$ & $\begin{array}{c}1.83^{* * *} \\
(0.49)\end{array}$ \\
\hline 4-2 $\times$ PUBLIC $\times$ Min & & $\begin{array}{l}-0.01 \\
(0.02)\end{array}$ & & \\
\hline $5-1 \times$ PUBLIC $\times$ Min & & $\begin{array}{c}0.00 \\
(0.03)\end{array}$ & & \\
\hline PUBLIC $\times \bar{c}_{-i, t-1}^{O}$ & & & $\begin{array}{c}0.002^{* * *} \\
(0.000)\end{array}$ & \\
\hline PUBLIC $\times \bar{c}_{-i, t-1}^{I}$ & & & $\begin{array}{c}0.003^{* * *} \\
(0.000)\end{array}$ & \\
\hline RESTRICTED $\times \bar{c}_{-i, t-1}$ & & & $\begin{array}{c}0.005 \\
(0.000)\end{array}$ & \\
\hline Control $\times \bar{c}_{-i, t-1}$ & & & $\begin{array}{c}0.005 \\
(0.000)\end{array}$ & \\
\hline No. of Lines & & & & $\begin{array}{c}0.00 \\
(0.00)\end{array}$ \\
\hline Statement & & & & $\begin{array}{l}1.22^{*} \\
(0.73)\end{array}$ \\
\hline Agreement & & & & $\begin{array}{c}-3.39^{* *} \\
(1.41)\end{array}$ \\
\hline Period & & & $\begin{array}{c}-0.01^{* * *} \\
(0.00)\end{array}$ & $\begin{array}{c}-0.16^{* * *} \\
(0.01)\end{array}$ \\
\hline Constant & $\begin{array}{c}0.49^{* * *} \\
(0.02)\end{array}$ & $\begin{array}{c}0.49^{* * *} \\
(0.02)\end{array}$ & $\begin{array}{c}0.37^{* * *} \\
(0.04)\end{array}$ & $\begin{array}{c}7.53^{* * *} \\
(0.57)\end{array}$ \\
\hline $\mathrm{N}$ & 7,200 & 7,200 & 6,840 & 6,480 \\
\hline
\end{tabular}

Sig. levels: ${ }^{* * *}: 1 \%,{ }^{* *}: 5 \%,{ }^{*}: 10 \%$.

Table 5: Random effects tobit estimates of contribution levels. 